\title{
PENERAPAN E-BANKING DALAM MENINGKATKAN JASA DAN LAYANAN PERBANKAN DI PT. BANK RAKYAT INDONESIA CABANG PADANG
}

\author{
Riska Nofia Safitri, Doni Marlius \\ Akademi Keuangan dan Perbankan Padang \\ donimarlius@akbpstie.ac.id
}

\begin{abstract}
Abstrack
Purpose of this study is to see the implementation of e-banking in improving services and banking services in PT. Bank Rakyat Indonesia Branch Padang. Samples of this study is the number of e-banking users and the number of customers of PT. Bank Rakyat Indonesia Padang Branch from 2014 to 2016.This study, using qualitative data analysis as a method of research that explains the Descriptive on the Application of E-Banking to Improve Services and Banking Services at PT. Bank Rakyat Indonesia Branch Padang.The method of analysis in terms of practices that need to be applied, so that can know the extent of implementation.These results indicate the application of e-banking in the PT. Bank Rakyat Indonesia in accordance with the standards set by Bank Indonesia, the implementation of e-banking can improve the quality of services and banking services as well as increase customer loyalty PT. Bank Rakyat Indonesia Branch Padang.
\end{abstract}

Keywords: Application, Services, E-Banking

PENDAHULUAN

Latar Belakang

Teknologi informasi ini bertujuan untuk mengimbangi kebutuhan manusia yang semakin lama semakin meningkat dan beraneka ragam. Seiring dengan tuntutan tersebut masyarakat semakin menuntut kepraktisan dalam berbagai aspek kehidupan. Salah satu teknologi informasi yang paling mendominasi saat ini adalah internet.
Internet merupakan system global dari seluruh jaringan computer yang saling terhubung menggunakan standar Internet Protocol Suite (ISP) unrtuk seluruh pengguna di dunia (http://id.m.wikipedia.org/wiki/internet

). Hasil survei yang dilakukan oleh Asosiasi Penyelenggara Jasa Internet Indonesia (APJII) Tahun 2015, secara nasional jumlah penggunaan internet dari tahun 2005 sampai 2014 secara umum meningkat. Hal tersebut dapat dilihat pada tabel dibawah ini: 


\section{Tabel Pertumbuhan Persentasi Dan Pengguna Internet \\ Tahun 2005-2014 \\ (Dalam Jutaan)}

\begin{tabular}{cccc}
\hline Tahun & $\begin{array}{c}\text { Jumlah Penduduk } \\
\text { Indonesia }\end{array}$ & $\begin{array}{c}\text { Jumlah Pengguna } \\
\text { Internet }\end{array}$ & $\begin{array}{c}\text { Persentasi } \\
\text { Pengguna Intemet }\end{array}$ \\
\hline 2005 & 206.3 & 16 & $7.8 \%$ \\
2006 & 212.7 & 20 & $9.4 \%$ \\
2007 & 219.2 & 20 & $9.1 \%$ \\
2008 & 225.6 & 25 & $11.1 \%$ \\
2009 & 232.1 & 30 & $12.9 \%$ \\
2010 & 238.5 & 42 & $17.6 \%$ \\
2011 & 242 & 55 & $22.7 \%$ \\
2012 & 245.5 & 63 & $25.7 \%$ \\
2013 & 248.9 & 71.2 & $28.6 \%$ \\
2014 & 252.4 & 88.1 & $34.9 \%$ \\
\hline
\end{tabular}

Sumber: Asosiasi Penyelenggara Jasa Internet Indonesia (APJII) 2015

Dari tabel di atas, pada tahun 2005 persentase pengguna internet adalah sebesar $7.8 \%$, selanjutnya tahun 2006 meningkat sebesar 9.4\%, sementara pada tahun 2007 terjadi penurunan sebesar $9.1 \%$. kemudian tahun 2008 kembali meningkat sebesar 11.1\%. lalu tahun 2009 terus meningkat sebesar $12.9 \%$. pada tahun 2010 meningkat sebesar $17.6 \%$, tahun 2011 juga mengalami peningkatan sebesar 22.7\%. pada tahun 2012 juga meningkat sebesar 25.7\%. tahun 2013 terus meningkat sebesar 28.6\%. dan pada tahun 2014 kembali meningkat sebesar $34.9 \%$. Berdasarkan data di atas, kehadiran internet kian berkembang dari tahun ke tahun, artinya internet menjadi salah satu jembatan bagi masyarakat dalam melakukan berbagai kegiatan.
Oleh karena itu, saat ini industri perbankan semakin gencar dalam membuat suatu sistem yang menggabungkan antara teknologi informasi dengan financial. Salah satu teknologi yang banyak digunakan perbankan adalah E-Banking atau disebut juga dengan Internet Banking.

Salah satu bank yang telah menerapkan layanan Internet Banking di Padang adalah Bank BRI Cabang Padang. Layanan ini semakin diminati oleh nasabah bank BRI Cabang Padang karena layanan internet banking memungkinkan para nasabah untuk mengakses layanan perbankan 24jam dengan biaya yang relatif murah. Berikut ini merupakan jumlah pengguna Internet Banking dan jumlah nasabah BRI Cabang Padang dari 2014 sampai 2016 adalah sebagai berikut: 
Tabel Jumlah Pengguna Internet Banking dan Jumlah Nasabah Bank BRI Tahun 2014 sampai 2016

\begin{tabular}{cccc}
\hline Periode & $\begin{array}{c}\text { Pengguna Internet } \\
\text { Banking }\end{array}$ & Jumlah Nasabah & $\begin{array}{c}\text { Persentase } \\
(\%)\end{array}$ \\
\hline 2014 & 2208 & 15510 & $14.2 \%$ \\
2015 & 3802 & 30943 & $12.3 \%$ \\
2016 & 3414 & 45968 & $7.4 \%$ \\
\hline
\end{tabular}

Sumber: PT. Bank Rakyat Indonesia, Tbk

Pada keterangan tabel di atas, pada tahun 2014 persentase pengguna internet banking sebesar $14.2 \%$, sedangkan pada tahun 2015 persentase pengguna internet banking mengalami penurunan sebesar $12.3 \%$. selanjutnya pada tahun 2016 persentase pengguna internet banking kembali menurun menjadi $7.4 \%$. Meskipun dari jumlah pengguna internet banking maupun jumlah nasabah BRI tahun 2014 sampai 2016 menunjukkan adanya kenaikan. Namun persentase pengguna internet banking di BRI Cabang Padang mengalami penurunan. ini disebabkan karena jumlah pengguna internet banking dari tahun ke tahun bertambah, akan tetapi masih tergolong rendah jika dibandingkan dengan jumlah keseluruhan nasabah BRI Cabang Padang. Melihat kenyataan diatas maka sangat penting bagi bank untuk meningkatkan jasa dan layanan yang mempengaruhi keputusan konsumennya atau nasabahnya dalam menggunakan layanan internet banking.

\section{Rumusan Masalah}

Adapun yang menjadi permasalahan yang akan penulis bahas dalam penelitian ini yaitu : Bagaimana Penerapan E-Banking Dalam Meningkatkan Jasa Dan Layanan Perbankan?

\section{Tinjauan Pustaka Perbankan}

Berdasarkan PSAK No. 31 tentang perbankan: Bank adalah suatu lembaga yang berperan sebagai perantara keuangan (financial intermediary) antara pihak yang memiliki kelebihan dana (surplus unit) dengan pihak pihak yang memerlukan dana (deficit unit), serta sebagai lembaga yang berfungsi memperlancar lalu lintas pembayaran

\section{Fungsi Bank}

Fungsi pokok bank umum yaitu :

a. Menyediakan mekanisme dan alat pembayaran yang lebih efisien dalam kegiatan ekonomi.

b. Menciptakan uang.

c. Menghimpun dana dan menyalurkannya kepada masyarakat.

d. Menawakan jasa - jasa keuangan lainnya.

\section{Jasa}

Kotler dan Keller dalam Tjiptono (2009),mendefenisikan jasa sebagai setiap tindakan atau perbuatan yang dapat ditawarkan oleh suatu pihak kepada pihak lain, yang pada dasarnya bersifat Intangible (tidak 
berwujud fisik) dan tidak menghasilkan kepemilikan sesuatu. Produk jasa dapat berhubungan denga produk fisik maupun tidak. Dalam hakikatnya, terdapat berbagai macam tingkat kombinasi antara barang fisik dan jasa intangible.

Kualitas Jasa

Ada beberapa perbaikan cara untuk memperhatikan kualitas jasa, yaitu:

a. Memberikan dukungan dan dorongan bagi karyawan yang berada di garis depan berupa otoritas tanggung jawab dan rangsangan untuk mengenali, peduli dan berorientasi kepada kebutuhan konsumen.

b. Mengembangkan motto "terobsesi kepada konsumen". Yaitu selalu memberikan kepuasan kepada kebutuhan konsumen terutama konsumen yang sudah terbukti kesetiaannya.

c. Melakukan komitmen terhadap kualitas, yaitu terhadap reformasi pelayanan dan bukan hanya keuangan dan bukan mengembangkan standar kualitas pelayanan yang tinggi senantiasa.

d. Memantau performasi pelayanan baik terhadap pelayanan perusahaan itu sendiri maupun pesaingnya. Metode yang digunakan dapat berupa belanja perbandingan, survei pelanggan, kertas saran dan keluhan.

e. Selalu mengkomunikasikan kepedulian terhadap kualitas pelayanan kepada para karyawan dan menyediakan performansi umpan balik.

f. Perusahaan harus memuaskan karyawannya seperti memuaskan para pelanggannya misalnya menciptakan lingkungan yang memberi dukungan kepada karyawan melebihi pelayanan terhadap performansi pelayanan yang baik dan memonitor kepuasan kerja. Hubungan yang baik antara para karyawan akan memberikan dukungan yang positif terhadap hubungan dengan pelanggan.

\section{Layanan}

Menurut Kotler (2002: 83) defenisi pelayanan adalah setiap tindakan atau kegiatan yang dapat ditawarkan oleh suatu pihak kepihak lain, yang pada dasarnya tidak berwujud dan tidak mengakibatkan kepemilikan apapun. Pelayanan merupakan perilaku produsen dalam rangka memenuhi kebutuhan dan keinginan konsumen demi tercapainya kepuasan konsumen itu sendiri. Pelayanan atau lebih dikenal dengan Service dapat di klasifikasikan sebagai :

a. Higt Contact Service, yaitu klasifikasi pelayanan jasa dimana kontak antara konsumen dan penyedia jasa yang sangat tinggi, konsumen selalu terlibat dalam proses layanan jasa itu sendiri.

b. Low Contact Service, yaitu klasifikasi pelayana jasa dimana kontak antara 
konsumen dengan penyedia jasa tidak terlalu tinggi.

E-Banking

Menurut Kamus Besar

Bahasa Indonesia (2005) E-Banking dapat didefinisikan sebagai jasa dan produk bank secara langsung kepada nasabah melalui elektronik, saluran komunikasi interaktif. $E$ Banking meliputi sistem yang memungkinkan nasabah bank, baik individu ataupun bisnis untuk megakses rekening, melakukan transaksi bisnis, atau mendapatkan informasi produk dan jasa bank melalui jaringan pribadi atau publik, termasuk internet. Nasabah dapat mengakses E-Banking melalui piranti pintar elektronik seperti komputer/PC, laptop, PDA,ATM atau telefon.

Sesuai dengan peraturan Bank Indonesia No. 5/8/PBI/2003 tanggal 19 Mei 2003 tentang penerapan menejemen resiko bank bagi bank umum (Lembaran Negara Republik Indonesia tahun 2003 Nomor 56, Tambahan Lembaran Negara Nomor 4292) serta keputusan direksi Bank Indonesia Nomor 27/164/KEP/DIR tanggal 31 maret tentang penggunaan teknologi system informasi oleh bank, maka pelaksanaan internet banking diatur oleh Bank Indonesia melalui Surat Edaran Bank Indonesia Nomor 6/18/DPNP tanggal 20 April 2004.

Berdasarkan Surat Edaran Bank Indonesia Nomor 6/18/DPNP tentang penerapan menejemen resiko pada aktifitas layanan jasa bank melalui internet, sehingga pendirian dan kegiatan internet-only bank tidak diperkenankan.

\section{Metode Penelitian}

Dalam pengumpulan data dan bahan untuk melakukan penelitian ini, digunakan metode-metode pengumpulan data sebagai berikut:

Metode Pengumpulan Data

1. Studi Pustaka (Library Research)

Penelitian yang dilakukan

ke perpustakaan beberapa buku-buku ilmiah dan tulisantulisan yang berhubungan dengan pembahasan yang dilakukan.

2. Studi Lapangan (Field Research)

Penelitian yang langsung objek penelitian di pilih untuk meneliti hasil data primer. Penelitian langsung ke lapangan ini akan dapat membantu penulis untuk melengkapi data yang diperlukan. Adapun cara riset lapangan ini adalah dengan mewawancarai pihak-pihak yang berkepentingan dalam hal ini adalah perusahaan atau instansi terkait.

\section{Metode Analisis Data}

Dalam menganalisa data, penulis menggunakan analisis data Kualitatif sebagai metode penelitian yang menjelaskan secara Deskriptif mengenai Penerapan E-Banking Dalam Meningkatkan Jasa dan Layanan Perbankan Di PT. Bank Rakyat Indonesia Cabang Padang. Metode analisis ditinjau dari dua praktek yang 
perlu diterapkan, sehingga dapat diketahui sejauh mana pelaksanaannya. Apakah perbedaan yang timbul menyangkut prinsip dasar konsep itu sendiri, pertanyaan itu akan terjawab selanjutnya dari hasil analisa itu digunakan sebagai dasar pengambilan kesimpulan dan saran.

\section{Hasil dan pembahasan}

Dalam rangka mengembangkan pertumbuhan ekonomi masyarakat, PT. Bank Rakyat Indonesia Cabang Padang menyediakan beberapa macam produk jasa. Salah satu diantaranya adalah penyediaan layanan e-banking kepada setiap masyarakat yang membutuhkan dan memenuhi syarat-syarat yang ditetapkan oleh bank.

Layanan e-banking PT. Bank Rakyat Indonesia Cabang Padang yaitu melakukan transaksi, pembayaran, dan transaksi lainnya melalui internet dengan website milik bank yang dilengkapi sistem keamanan, yang terdiri dari ATM BRI, E-BUZZ, BRIZZI, BRILINK, SMS Banking BRI, KIOS BRI, MOCASH, Internet Banking, MINI ATM BRI, EDC Merchant.

\begin{tabular}{l}
\multicolumn{2}{c}{ Alternatif } & penyelesaian \\
masalah atau hambatan- \\
hambatan dalam penggunaan \\
dapat melaporkannya kepada \\
customer service. Selanjutnya \\
customer service r akan \\
melaporkan komplain nasabah
\end{tabular}

tersebut kepada atasan, dan atasan akan memberi solusi terbaik kepada nasabah. BRI menggunakan 3 (tiga) lapis sistem pengamanan untuk melindungi akses dan transaksi Anda di internet banking BRI yaitu :

a. Secure Socket Layer ("SSL")

SSL adalah teknologi pengamanan yang 'mengacak' jalur antar komputer sehingga tidak dapat dibaca oleh pihak lain.

b. User ID dan Password

c. mToken BRI

mToken adalah teknologi pengamanan tambahan yang selalu menghasilkan password yang berbeda setiap kali digunakan.

Karena banyaknya variasi browser internet yang ada, sulit untuk menyediakan internet banking yang mengikuti keamanan masing-masing browser. Saat ini BRI hanya menyediakan sarana internet banking yang lebih cocok diakses dengan menggunakan Microsoft Internet Explorer versi 7 ke atas, Mozilla Firefox versi 2.0.0 ke atas atau Safari versi 4.0.3 ke atas. Kebijakan yang dilakukan oleh PT. Bank Rakyat Indonesia Cabang Padang dalam melakukan aktivitas registrasi Internet banking adalah sebagai berikut: 
A. Syarat Pendaftaran Internet Banking

1) Untuk menggunakan layanan Internet banking BRI pastinya nasabah terlebih dahulu harus menjadi nasabah BRI dengan cara membuka rekening disana.

2) Telah memiliki ATM BRI

3) Memiliki ponsel dengan nomor operator partner BRI (telkomsel, indosat, $\mathrm{xl}$, mobile- 8 dll)

4) Nasabah memiliki email untuk menerima pemberitahuan setiap transaksi yang dilakukan.(selain verifikasi mtoken ke ponsel)

B. Langkah Pendaftaran

1. Daftar melalui Customer Service

Pendaftaran dan aktivasi internet banking BRI bisa dilakukan melalui ATM atau langsung pergi ke kantor BRI terdekat dan mendaftar ke Customer Service. Nasabah harus membaea ponsel serta nomor yang akan didaftarkan untuk mToken. Nantinya nasabah akan menerima sms verifikasi untuk aktivasi sms banking.

2. Daftar melalui mesin ATM
a) Pergi ke ATM dan masukan ATM kemudian masukan password/PIN
b) Pilih menu Lainnya
c) Kemudian pilih menu Registrasi
d) Selanjutnya pilih menun Internet Banking

e) Kemudian nasabah akan diperintahkan memasukan password baru untuk layanan internet banking berjumlah 6 digit. (password boleh berbeda dengan password ATM)

f) Kemudian nasabah akan diminta mengulang pasword yang anda masukan tadi sekali lagi.

g) Apabila pendaftaran internet banking berhasil maka mesin ATM akan memunculkan USERID internet banking nasabah kemudian di cetak di struk yang berisi USERID dan Password. Umumnya USERID berupa gabungan nama dan angka tanggal lahir nasabah.

h) Selanjutnya jangan lupa untuk mengingat/menyimpan informasi yang di cetak tadi bisa di note hp atau catatan lainya sekiranya tidak lupa.

C. Cara menggunakan Internet Banking BRI

Untuk mengakses layanan internet bangking BRI anda bisa membuka situnya yaitu di https://ib.bri.co.id.

a) Masukan USERID dan password yang di dapat dari ATM tadi kemudian klik tombol masuk

b) Setelah masuk nasabah akan dihadapkan dengan halaman syarat dan ketentuan layanan Internet Banking BRI, baca dan pelajari. Jika anda setuju silahkan klik tombol setuju 
c) Kemudian nasabah diarahkan untuk merubah password dari mesin ATM tadi dan diminta memasukan email

d) Sampai disni nasabah telah berhasil melakukan pendaftaran internet banking BRI.

Perlu diketahui sampai pada tahap tersebut nasabah hanya bisa menggunakan layanan internet banking untuk melakukan cek saldo dan pemindah bukuan saja. Nasabah belum bisa melakukan trasfer, pembayaran, dan sejenisnya sampai nasabah mengaktifkan mToken.

D. Aktivasi m-Token BRI

Untuk melakukan aktivasi dan mendapatkan mToken BRI nasabah harus pegi ke kantor BRI untuk menemui Customer Service dengan membawa foto copy KTP, buku tabungan, ATM, dan hp dengan nomor ponsel utama nasabah yang akan di jadikan mToken.

\section{Kesimpulan dan Saran}

Kesimpulan

Dilihat dari hasil penelitian

Penerapan e-banking dalam meningkatkan jasa dan layanan perbankan di PT. Bank Rakyat Indonesia Cabang Padang berjalan dengan lancar dan sesuai dengan apa yang diharapkan. Prosedur penggunaan e-banking dilakukan sesuai dengan proses dan peraturan yang berlaku. Bank memberikan pelayanan yang baik kepada nasabahnya sehingga apa yang dibutuhkan nasabah dapat dipenuhi oleh bank.

Saran
Sebaiknya untuk menarik nasabah PT. Bank Rakyat Indonesia Cabang Padang menempatkan upaya-upaya promosi seperti memasang spanduk dan iklan yang bertujuan memberitahukan kepada masyarakat tentang produk dan layanan yang ada di PT. Bank Rakyat Indonesia Cabang Padang. Untuk menjaga loyalitas pelanggan, perlu sekali ditingkatkan kualitas jasa dan layanan PT. Bank Rakyat Indonesia Cabang Padang dengan mrnciptakan inovasi terbaru agar nasabah mudah, aman dan nyaman dalam melakukan berbagai transaksi E-Banking. Pihak Bank seharusnya mmelakukan pengecekan jaringan internet banking secara berkala agar dapat meminimalisir berbagai resiko yang mugkin akan terjadi.

\section{DAFTAR PUSTAKA}

Astuti Santi Dwi. 2012. Analisis Faktor-Faktor Yang

Mempengaruhi Keputusan Konsumen Dalam

Menggunakan Layanan Internet Banking Di Bank Bukopin. Skripsi Pada Fakultas Ekonomi Bisnis Universitas Telkom.

Griffin. 2005. Customer Loyalty: Menumbuhkan Dan Mempertahankan Kesetiaan Pelanggan (Terjemahan). Jakarta. Erlangga.

Kasmir. 2010. Dasar-Dasar Perbankan. Jakarta. Grafindo. 
Kotler, Philip and Keller, Kevin. 2009.

Managemen

Pemsaran.

Edisi13. Erlangga.

Lukitasari, Fakih. 2011. Analisis EBanking Dalam Meningkatkan Jasa Dan Layanan Perbankan Di Bank Tabungan Negara KCP Sukoharjo. Tugas Akhir Pada Fakultas Ekonomi Universitas Sebelas Maret.

Lupiyoadi. 2004. Managemen Pemasaran Jasa, Teori dan Praktek. Edisi Pertama. Jakarta. Salemba Empat.

Putri Novita Dwi. 2010. Faktor-Faktor

Customer

Management

Berpengaruh Relationship

Loyalitas Nasabah PT. Bank
BRI Unit Duren Jaya Bekasi. Skripsi Pada Fakultas Dan Managemen Institut Pertanian Bogor.

Rambat. 2001. Managemen Pemaaran Jasa, Teori dan Praktek. Edisi Pertama. Jakarta. Salemba Empat.

Tjiptono, Fandi. 2005. Pemasaran Jasa. Edisi 1. Malang. Bayumedia

Tjiptono, Fandi. 2006. Menegemen Jasa. Yogyakarta. Andi.

Zakaria, Aziz. 2012. Analisis Pengaruh Penerapan Internet Banking Terhadap Kinerja Perbankan Di Indonesia. Skripsi Pada Fakultas Ekonomi Universitas Indonesia. 